\title{
Laboratory leaching tests on treated wood according to different harmonised test procedures
}

\author{
Ute Schoknecht $^{1 *}$, Ute Kalbe ${ }^{2}$, André van Zomeren ${ }^{3}$ and Ole Hjelmar ${ }^{4}$
}

\begin{abstract}
Background: Laboratory leaching tests on treated wood were performed during a European robustness study in the framework of the validation of a tank leaching test procedure that has been proposed for construction products in order to determine the potential release of dangerous substances which can be transferred to soil and groundwater. The release of substances has to be determined also for materials treated with biocidal products according to the requirements of the European Biocidal Products Regulation. A similar leaching test procedure was already harmonised for treated wood for this purpose. Both test procedures were applied in parallel to wood treated with the same preservative to investigate whether the results of these tests can replace each other. Additional experiments were performed to further investigate unexpected effects of $L / A$ ratio on leaching of copper and duration of storage of treated test specimens.

Results: Both procedures generate similar results concerning cumulative emissions of tebuconazole, copper, dissolved organic carbon and total nitrogen. The emission rates with time are in comparable ranges for both leaching protocols. Emissions of copper increased with decreasing L/A ratios. Strong correlation of copper concentrations and dissolved organic carbon as well as total nitrogen concentrations in eluates indicates that this observation is caused by co-elution of copper with organic substances. Duration of storage of treated test specimens affected emissions for the investigated wood preservative.

Conclusions: Based on these findings, results from both test procedures can be used to describe leaching characteristics and avoid double testing of treated wood to fulfil the requirements of the European regulations for either biocides or construction products. Leaching of substances from treated wood is a complex process that depends on its chemical composition and ageing processes.
\end{abstract}

Keywords: Construction products; Biocidal product; Emission; Leaching; Tank leaching test; Treated wood; European regulation

\section{Background}

The EU member states require that construction works are designed and executed so as not to endanger the safety of persons, domestic animals or property nor damage the environment within the Construction Products Regulation [1]. This includes concern about possible emissions of harmful substances due to contact of construction products with water.

\footnotetext{
* Correspondence: ute.schoknecht@bam.de

'Division 4.1 Biodeterioration and Reference Organisms, BAM Federal Institute for Materials Research and Testing, Unter den Eichen 87, D-12205 Berlin, Germany

Full list of author information is available at the end of the article
}

CEN/TC 351/WG 1 'Release from construction products into soil, ground water and surface water' was mandated to develop harmonised laboratory leaching tests and to test the applicability of these methods for a series of different construction products within a robustness study as a part of the validation process [2]. The results of this study were reported by Hjelmar et al. [3].

A dynamic surface leaching test (DSLT) has been proposed for testing of monolithic materials and described in a Draft Technical Specification (FprCEN/TS 166372:2013 [4], temporarily named TS-2). This procedure is intended to also apply for structural timber since it is considered a 'monolithic product'. Therefore, timber was 
included in the robustness study. It was decided to use wood specimens treated with a wood preservative to assure that methods for the quantification of inorganic as well as organic substances in the eluates were available and that the experiments provide data for the evaluation of the test procedure.

Leaching of inorganic and to some extent also organic components of wood preservatives from treated wood has been investigated for many years with respect to the type of preservative, leaching mechanisms, environmental impact and test conditions [5-13]. Reduction of leaching has been a driving force for the development of new types of wood preservatives. However, leaching of active substances from treated wood can be intended to some extent to avoid growth of microorganisms in a water film on wet surfaces or soil in the surrounding area of wood. Therefore, a precautionary environmental risk assessment remains relevant for treated wood.

During the European robustness study, tebuconazole and copper from the applied wood preservative were analysed in the eluates. The effects of temperature as well as different ratios between water volume and exposed surface area (L/A ratio) on the test results were investigated.

The robustness study revealed that tebuconazole emissions decreased slightly with decreasing L/A ratios, whereas the emissions of copper from treated wood - surprisingly increased with decreased amounts of water. The experiments did not indicate dependency on the temperature between $10^{\circ} \mathrm{C}$ and $27^{\circ} \mathrm{C}$ since the differences in the results were in the range of the relative standard deviations between parallel tests. There were hints that the results were also affected by the duration of storage of the treated test specimens.

Treated and untreated timber was investigated according to a water renewal scheme lasting for 36 days. However, based on experiments on other construction products, a 64-day scheme was selected for the final TS-2 draft [3].

In additional experiments, the results of the TS-2 test for construction products were compared to results from tests that were developed for treated wood by CEN/TC 38 'Durability of wood and wood-based products' and by the OECD Task Force on Biocides in order to fulfil the requirements of the regulations on biocidal products [14]. These tests were designed for different use conditions, i.e. permanent and occasional contact with water [15-18]. The test procedures for wood in permanent contact with water - OECD 313 [17] and CEN/ TS 15119-2 [16] - correspond to a DSLT. The test parameters are similar for all three procedures with only a few deviations, e.g. different L/A ratios (see Table 1). The required L/A ratio and sampling scheme are the same in OECD 313 and CEN/TS 15119-2:2012. Therefore, in this paper, the procedures for treated wood will be referred to as 'OECD 313'.
Parallel experiments according to TS-2 (preliminary name, intended final name is CEN/TS 16637-2) and OECD 313 were performed to investigate whether the results of both procedures can replace each other to fulfil the requirements of both the European regulations in order to avoid double testing. Additional experiments at different L/A ratios and after a long period of storage of the treated test specimens were performed to further investigate unexpected effects that were observed during the robustness study.

This report is directed at the comparison of TS-2 and OECD 313 tests, variability of test results from leaching experiments on treated wood and confirmation of effects of the variation of L/A ratios and ageing of the treated test specimens on emissions of the selected substances.

\section{Results and discussion}

\section{Comparison of TS-2 and OECD 313 experiments}

Emission curves for tebuconazole, copper, dissolved organic carbon (DOC) and total nitrogen (TN) from parallel TS-2 and OECD 313 experiments are presented in Figure 1 . The replicates investigated at conditions stipulated in the current documents for both leaching tests were selected for this comparison. Both TS-2 and OECD 313 experiments yield similar leaching curves for each of the considered substances despite of slight deviations of parameters.

It has to be considered that similar emission rates in TS-2 and OECD 313 experiments mean higher concentrations of these components in the eluates from the OECD 313 experiments, since the standardised L/A ratios applied for the comparison were 8 and $2.5 \mathrm{~cm}^{3} / \mathrm{cm}^{2}$, respectively (see Tables 1 and 2).

Standard deviations between parallel test assemblies are usually lower for test assemblies using sets of five test specimens as required in OECD 313 than for tests using a single test specimen as allowed for TS-2 experiments since differences in surfaces of test specimens are compensated to a certain extent if wood samples are combined. Relative standard deviations of tebuconazole concentrations in the eight eluate fractions (i.e. samples obtained after the defined immersion periods) from parallel experiments were $11 \%$ ( $3 \%$ to $24 \%$ ) in TS-2 experiments using two test specimens per test assembly and 6\% (3\% to $10 \%$ ) in OECD 313 experiments. Relative standard deviations of copper concentrations in the corresponding eluate fractions of parallel experiments were $14 \%$ (6\% to $42 \%$ ) in TS-2 experiments and 2\% (1\% to 5\%) in OECD 313 experiments. The maximum standard deviations for the TS-2 experiments were observed for the first eluate fractions that were obtained after $2 \mathrm{~h}$ of immersion. This observation probably reflects concentration differences on the surface of the test specimens at the beginning of the test. 
Table 1 Test setup for the applied version of TS-2 and CEN/TS 15119-2 as well as OECD 313 experiments using treated wood

\begin{tabular}{|c|c|c|c|c|c|c|}
\hline Parameter & \multicolumn{3}{|l|}{ TS-2 } & \multicolumn{3}{|c|}{ CEN/TS 15119-2 and OECD 313} \\
\hline \multirow{4}{*}{$\begin{array}{l}\text { Test specimens and treatment } \\
\text { with wood preservatives }\end{array}$} & \multicolumn{3}{|c|}{ Representative of the product to be tested } & \multirow{2}{*}{\multicolumn{3}{|c|}{$\begin{array}{l}\text { Quality parameters for wood are defined (e.g. 100\% sapwood), } \\
\text { reference to EN } 113\end{array}$}} \\
\hline & \multirow{3}{*}{\multicolumn{3}{|c|}{$\begin{array}{l}\text { Preparation procedure to be developed by the } \\
\text { respective product Technical Committees }\end{array}$}} & & & \\
\hline & & & & \multicolumn{3}{|c|}{$\begin{array}{l}\text { Treatment and conditioning of test specimens as in accordance } \\
\text { with either the recommendations made by the supplier, } \\
\text { commercial treatment practices or EN } 252\end{array}$} \\
\hline & & & & \multicolumn{3}{|c|}{$\begin{array}{l}\text { Test specimens with a retention within } 5 \% \text { of the mean are } \\
\text { selected and end-sealed to prevent leaching via the end grain }\end{array}$} \\
\hline \multirow[t]{3}{*}{ Test assemblies } & \multicolumn{3}{|c|}{ At least one test piece per test assembly } & \multirow{2}{*}{\multicolumn{3}{|c|}{$\begin{array}{l}\text { TS 15119-2: exposed surface area: } \geq 200 \mathrm{~cm}^{2} \text {, number of } \\
\text { test specimens per test assembly: } \geq 3\end{array}$}} \\
\hline & \multicolumn{3}{|c|}{ Monolithic products: all dimensions $>40 \mathrm{~mm}$} & & & \\
\hline & $\begin{array}{l}\text { Flat } p \\
\text { of exp } \\
<40 \mathrm{r}\end{array}$ & $\begin{array}{l}\text { ducts (sheet-like ar } \\
\text { sed surface area: } 10\end{array}$ & $\begin{array}{l}\text { olate-like): minimum } \\
\mathrm{m}^{2} \text {, one dimension }\end{array}$ & \multicolumn{3}{|c|}{$\begin{array}{l}\text { OECD 313: sets of five test specimens according to EN } 113 \text { size } \\
\text { blocks are recommended (yield } 200-\mathrm{cm}^{2} \text { exposed surface area) }\end{array}$} \\
\hline \multirow[t]{2}{*}{ Water } & \multirow{2}{*}{\multicolumn{3}{|c|}{$\begin{array}{l}\text { Demineralised water or deionised water or water } \\
\text { of equivalent purity with a conductivity }<0.5 \mathrm{mS} / \mathrm{m} \\
\text { according to grade } 3 \text { specified in ISO } 3696\end{array}$}} & \multicolumn{3}{|c|}{$\begin{array}{l}\text { CEN/TS 15119-2: water complying with grade } 3 \text { of EN ISO 3696, } \\
\text { water especially designed for environmental investigations or } \\
\text { deionised water, pH } 5 \text { to } 7 \text { (not adjusted) }\end{array}$} \\
\hline & & & & \multicolumn{3}{|c|}{$\begin{array}{l}\text { OECD 313: deionised water is recommended, synthetic seawater has } \\
\text { to be used when wood exposed to seawater is to be evaluated }\end{array}$} \\
\hline L/A ratio & \multicolumn{3}{|c|}{$8 \mathrm{ml} / \mathrm{cm}^{2}$} & \multicolumn{3}{|c|}{$2.5 \mathrm{ml} / \mathrm{cm}^{2}$} \\
\hline Temperature & \multicolumn{3}{|c|}{$20^{\circ} \mathrm{C}^{\mathrm{a}}$} & \multicolumn{3}{|c|}{$20^{\circ} \mathrm{C} \pm 2^{\circ} \mathrm{C}$} \\
\hline \multirow[t]{9}{*}{ Sampling schemes ${ }^{a}$} & Day & $\begin{array}{l}\text { Sample number } \\
\text { (eluate fraction) }\end{array}$ & $\begin{array}{l}\text { Total duration of } \\
\text { the test [days] }\end{array}$ & Day & $\begin{array}{l}\text { Sample number } \\
\text { (eluate fraction) }\end{array}$ & $\begin{array}{l}\text { Total duration of } \\
\text { the test [days] }\end{array}$ \\
\hline & 1 & 1 & 0.08 & 1 & 1 & 0.25 \\
\hline & 2 & $2^{\mathrm{b}}$ & 1 & 2 & 2 & 1 \\
\hline & 3 & 3 & 2.25 & 3 & 3 & 2 \\
\hline & 9 & $4^{\mathrm{b}}$ & 8 & 5 & 4 & 4 \\
\hline & 15 & 5 & 14 & 9 & 5 & 8 \\
\hline & 16 & 6 & 15 & 16 & 6 & 15 \\
\hline & 29 & $7^{b}$ & 28 & 23 & 7 & 22 \\
\hline & 37 & 8 & 36 & 30 & 8 & 29 \\
\hline
\end{tabular}

${ }^{\mathrm{a} F p r C E N / T S ~} 16637-2$ defines a sampling scheme including eight immersion periods (steps) within 64 days and temperature of $22^{\circ} \mathrm{C} \pm 3^{\circ} \mathrm{C}$ as a result of the robustness

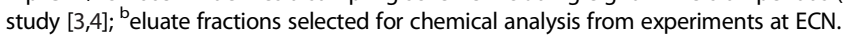

The $\log$-log graphs in Figure 1 include lines with a slope of -0.5 that indicate periods during the experiments when leaching can be assumed to be mainly controlled by diffusion. Diffusion-controlled processes are expected to be proportional to the square root of time (i.e. exponent 0.5 ). This exponent becomes factor 0.5 in logarithmic functions of cumulative emissions and -0.5 in logarithmic functions of emission rates with time. During the early stage of the experiments, the emission curves of all components follow the lines with a slope of -0.5 almost parallel, i.e. leaching is mainly controlled by diffusion. Steeper graphs indicate depletion after longer periods of permanent immersion. The applied TS-2 sampling scheme includes a short immersion step from the 14th to the 15th day. This caused relatively high emission rates for tebuconazole during this immersion period (see Figure 1a), but not for $\mathrm{Cu}, \mathrm{DOC}$ and $\mathrm{TN}$. For tebuconazole and copper, these observations are in agreement with former experiments $[9,11]$. It is assumed that leaching of tebuconazole is restricted due to its low water solubility $(29 \mathrm{mg} / \mathrm{l}$ at $20^{\circ} \mathrm{C}$, independent of $\left.\mathrm{pH}[19]\right)$. Providing fresh water strongly supports leaching of this substance.

The cumulative emissions of three parallel experiments at standardised conditions during the first series of experiments exhibited a very good repeatability (see Table 2 and Figure 2). The cumulative emissions of tebuconazole, copper and DOC were in similar ranges for TS-2 and OECD 313 experiments (see results for the first test series in Table 2). The relative standard deviations of the cumulative emissions during the experiments were similar for TS-2 and OECD 313 experiments.

Higher emissions of tebuconazole in the TS-2 experiment were probably caused by the higher amount of water per unit surface area, whereas slightly higher emissions of copper in OECD 313 experiments were probably caused by higher DOC concentrations in the eluates from this test.

The total emissions during the tests according to OECD 313 differed slightly between experiments using 

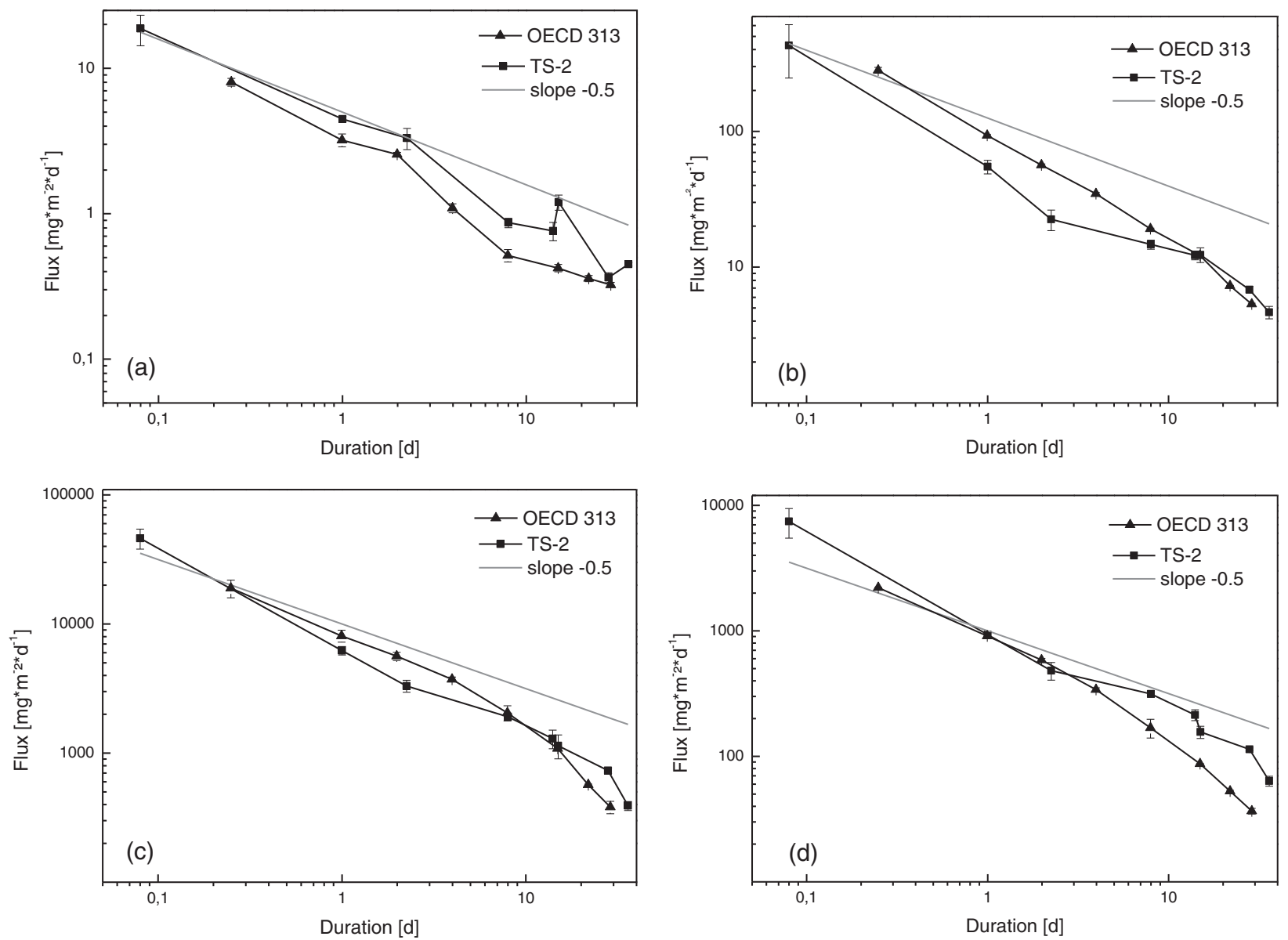

Figure 1 Emission curves for tebuconazole, copper, DOC and TN from parallel TS-2 and OECD 313 experiments. Leaching of tebuconazole (a), copper (b), DOC (c) and TN (d) from the first series of TS-2 experiments at L/A =8 $\mathrm{cm}^{3} / \mathrm{cm}^{2}$ and OECD 313 experiments $(n=3$ for each method). Quadrates $(\boldsymbol{-})$ represent data from TS-2 experiments, triangles $(\boldsymbol{\Lambda})$ represent data from OECD 313 experiments and error bars indicate standard deviation. The straight lines have a slope of -0.5 .

sets of five test specimens and the test using a single test specimen from the same origin as the specimens for the TS-2 test (see data for experiments of series 1 in Table 2 and Figure 2). This is probably caused by different origins and ages of the wood.

Cumulative DOC emissions from experiments on treated wood are about $20 \%$ higher than DOC emissions from the control experiments using untreated wood specimens (Table 2). This difference is obviously caused by components of the wood preservative.

Most of the TN in the eluates is related to treatment with the wood preservative that includes amines (see Table 2). It was shown by Lupsea et al. [20] that nitrogen is not only leached as the added amine but also as a series of substances that originate from reactions of nitrogen (amino group) contained in the wood preservative with wood components. Higher TN emissions in TS-2 experiments can be caused by different evaporations of ethanolamine during the 39-day period of conditioning of the treated test specimens prior to the leaching experiment. The amount of evaporated ethanolamine was probably higher from the small test specimens used for OECD 313 experiments having a ratio between surface area and volume of $2.50 \mathrm{~cm}^{2} / \mathrm{cm}^{3}$ compared to a ratio of $1.24 \mathrm{~cm}^{2} /$ $\mathrm{cm}^{3}$ for the 'stakes' used for TS-2 experiments.

The mass of the wood specimens increased until 29 days of immersion in the OECD 313 procedure. The wood moisture content, as calculated from the mass data, increased from about $12 \%$ to $50 \%$. This is close to the upper values that have been reported to range between $30 \%$ and $55 \%$ for wood exposed to precipitation [13].

The $\mathrm{pH}$ of the eluates from TS- 2 and OECD 313 experiments ranged between $\mathrm{pH} 4.7$ and 5.8 for untreated wood and usually between pH 6.5 and 7.5 (up to pH 8.6 in one experiment) for treated wood (see Table 2). An increase of the $\mathrm{pH}$ in the eluates from the treated wood specimens has to be expected. It is caused by leaching of alkaline ethanolamine that is part of the wood preservative. 
Table 2 Test data from TS-2 (mg/m $\mathrm{m}^{2}$ in 36 days) and OECD 313 (mg/m $\mathrm{m}^{2}$ in 29 days) experiments

\begin{tabular}{|c|c|c|c|c|c|c|c|c|c|c|c|c|}
\hline \multirow{3}{*}{$\begin{array}{l}\begin{array}{l}\text { Duration } \\
\text { of storage }^{a}\end{array} \\
\text { [weeks] }\end{array}$} & \multirow{3}{*}{$\begin{array}{l}\text { Name of the } \\
\text { experiment }\end{array}$} & \multirow[t]{3}{*}{ Repetition } & \multicolumn{8}{|c|}{ Cumulative emission } & \multicolumn{2}{|c|}{$\mathrm{pH}$ range } \\
\hline & & & \multicolumn{2}{|l|}{$\mathrm{Cu}$} & \multicolumn{2}{|c|}{ Tebuconazole } & \multicolumn{2}{|l|}{ DOC } & \multicolumn{2}{|l|}{$\mathrm{TN}$} & \multirow[t]{2}{*}{ Max } & \multirow[t]{2}{*}{ Min } \\
\hline & & & {$\left[\mathrm{mg} / \mathrm{m}^{2}\right]$} & SD & {$\left[\mathrm{mg} / \mathrm{m}^{2}\right]$} & SD & {$\left[\mathrm{mg} / \mathrm{m}^{2}\right]$} & SD & {$\left[\mathrm{mg} / \mathrm{m}^{2}\right]$} & SD & & \\
\hline \multirow[t]{9}{*}{7} & L/A 8 control & & $<\mathrm{LOD}$ & & $<\mathrm{LOD}$ & & 37,445 & & 126 & & 5.83 & 4.76 \\
\hline & L/A 2.2 & 1 & 591 & & 19.5 & & 44,678 & & 7,955 & & 7.21 & 6.46 \\
\hline & L/A 5 & 1 & 510 & & 28.5 & & 47,214 & & 7,603 & & 7.37 & 6.34 \\
\hline & L/A 8 & 1 & 426 & & 29.3 & & 46,852 & & 7,497 & & 7.40 & 6.37 \\
\hline & & 2 & 399 & & 27.9 & & 44,744 & & 7,160 & & 7.96 & 6.24 \\
\hline & & 3 & 401 & & 29.4 & & 46,797 & & 7,218 & & 7.27 & 6.45 \\
\hline & L/A 9 & 1 & 450 & & 31.2 & & 45,464 & & 7,572 & & 7.44 & 6.55 \\
\hline & L/A 8 & Mean & 409 & 15 & 28.9 & 0.8 & 46,131 & 1,201 & 7,292 & 180 & & \\
\hline & All experiments & Mean & 463 & 75 & 27.6 & 4.1 & 45,958 & 1,135 & 7,501 & 289 & & \\
\hline \multirow[t]{8}{*}{39} & L/A 8 rep control & & $<\mathrm{LOD}$ & & $<\mathrm{LOD}$ & & 13,550 & & 352 & & 5.86 & 4.75 \\
\hline & L/A 2.2 rep & 2 & 1,036 & & 20.0 & & 34,654 & & 6,139 & & 6.96 & 6.24 \\
\hline & & 3 & 1,000 & & 19.9 & & 34,024 & & 5,706 & & 7.29 & 6.10 \\
\hline & L/A 5 rep & 2 & 867 & & 28.7 & & 34,746 & & 5,968 & & 7.52 & 6.28 \\
\hline & L/A 8 rep & 4 & 764 & & 39.2 & & 36,443 & & 6,047 & & 7.81 & 6.34 \\
\hline & & 5 & 890 & & 39.0 & & 36,470 & & 6,126 & & 8.61 & 6.35 \\
\hline & L/A 8 & Mean & 827 & & 39.1 & & 36,457 & & 6,087 & & & \\
\hline & All experiments & Mean & 911 & 109 & 29.4 & 9.6 & 35,267 & 1,121 & 5,997 & 177 & & \\
\hline \multirow[t]{7}{*}{8} & OECD 313 control & & $<\mathrm{LOD}$ & & $<\mathrm{LOD}$ & & 32,405 & & 139 & & 5.03 & 4.72 \\
\hline & OECD 313 & 1 & 499 & & 18.8 & & 44,670 & & 4,337 & & 6.80 & 6.40 \\
\hline & & 2 & 520 & & 19.6 & & 45,876 & & 4,320 & & 6.78 & 6.50 \\
\hline & & 3 & 503 & & 17.6 & & 46,134 & & 4,569 & & 6.75 & 6.45 \\
\hline & OECD 313 & Mean & 507 & 11 & 18.7 & 1.0 & 45,273 & 782 & 4,409 & 139 & & \\
\hline & OECD $313^{a}$ control & & & & & & 22,326 & & 76 & & 4.60 & 4.22 \\
\hline & OECD $313^{a}$ & 1 & 425 & & 22.5 & & 37,550 & & 6,308 & & 7.12 & 6.60 \\
\hline 68 & OECD $313^{\mathrm{a}}$ rep & 2 & 834 & & 16,9 & & b & & $\mathrm{b}$ & & 6.04 & 5.59 \\
\hline
\end{tabular}

Experiments at conditions stipulated in TS-2 and OECD 313 are indicated by italics. Mean data of parallel experiments according to these conditions are indicated by italic entries. ${ }^{a}$ 'Duration of storage' refers to treated test specimens. SD, standard deviation $\left(\mathrm{mg} / \mathrm{m}^{2}\right)$; 'control', experiment with untreated wood; OECD 313, test specimens $\left(1.5 \times 2.5 \times 5 \mathrm{~cm}^{3}\right)$; OECD $313^{\mathrm{a}}$, test specimen as in TS-2 $\left(2.5 \times 5 \times 15 \mathrm{~cm}^{3}\right)$.

${ }^{b}$ During the first four immersion periods ( 4 days), DOC emissions were about $80 \%$, and TN emissions were about $50 \%$ of the amounts detected during the same period of time in the related experiment with test specimens after 8 weeks of storage of the treated test specimens.
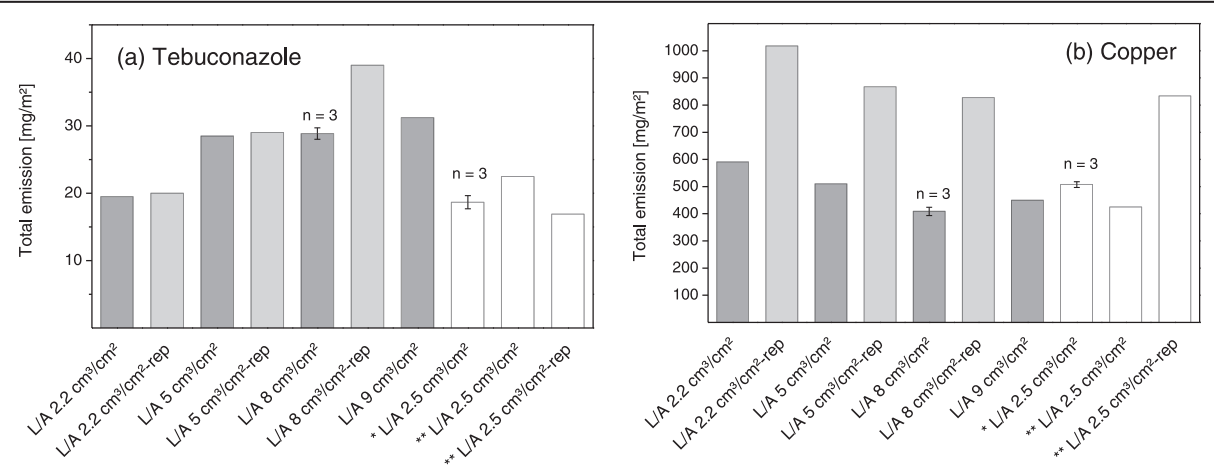

Figure 2 Cumulative emission of tebuconazole and copper in both series of TS-2 experiments and OECD 313 experiments. Cumulative emission of tebuconazole (a) and copper (b) in both series of TS-2 experiments (first series: dark grey columns, repeated experiments: grey columns) and OECD 313 experiments using small test specimens $\left(^{*}\right)$ and test specimens as in TS-2 tests (**) (white columns). Error bars indicate standard deviation. The numbers of replicates are given in Table 2. 


\section{Variability of test results from leaching experiments on treated wood}

TS-2 experiments at standardised conditions $\left(\mathrm{L} / \mathrm{A}=8 \mathrm{~cm}^{3} /\right.$ $\mathrm{cm}^{2}, 20^{\circ} \mathrm{C} \pm 2^{\circ} \mathrm{C}$; later defined to be $22^{\circ} \mathrm{C} \pm 3^{\circ} \mathrm{C}$ in FprCEN/ TS 16637-2:2013) were performed at BAM and ECN with three parallel test assemblies in both laboratories (see Table 3). The test samples originate from the same batch but had to be shipped to ECN Petten. The experiments at BAM were started 7 and 39 weeks after treatment, and the experiments at ECN were started 17 weeks after treatment due to the schedule of all experiments within the robustness study at ECN. The eluate fractions 2, 4 and 7 from the ECN experiments were shipped to BAM immediately after sampling. All samples were analysed at BAM for tebuconazole and copper. The measured concentrations are summarised in Figure 3.

Results that fall within the average $\pm 2.8 \mathrm{SD}$ range for the standardised conditions were regarded to be in the same range in the robustness study [3]. If this criterion is applied, and the results of the first experiments performed at BAM (without shipment of test specimens and eluate samples, shortest period of storage after treatment) were regarded as reference values, some of the tebuconazole and copper concentrations of the eluate fractions from the ECN experiment just fit. The tebuconazole concentrations tend to be lower, whereas the copper concentrations tend to be higher for the ECN experiments compared to the results from the BAM experiment. Relatively high deviation of tebuconazole concentrations in the second fractions and copper concentrations in the fourth fractions were observed for the three parallel experiments at ECN Petten. This is probably not caused by uncertainty of the analytical methods or analytical outliers. Relative standard deviations of tebuconazole concentrations from three parallel injections were $1 \%$ to $2 \%$ for all samples. Tebuconazole concentrations in two samples of eluate fraction 2 were considerably lower than the data from the experiment at BAM, whereas the concentration of the third sample was similar to the data from the BAM experiment. Variation of copper concentrations was generally higher in the experiment at ECN than at BAM - perhaps due to the fact that a single test specimen per test assembly was used in the experiments at ECN whereas two test specimens were combined in the test assemblies at BAM (see Table 3).

Several parameters cause differences of analytical results within and between the tests at the participating laboratories. The subsamples were taken from the same parts of the treated stakes and randomly distributed to ECN and BAM. However, samples of treated wood cannot be homogenous. In addition, the wood samples as well as the eluates were shipped to and from ECN Petten, whereas the wood samples were stored under controlled conditions and the eluates were analysed directly after sampling at BAM. This should not affect copper concentrations, but shipment might potentially reduce the concentration of tebuconazole. Possibly, this is an explanation for lower tebuconazole concentrations in the samples from ECN.

\section{Variation of L/A ratios}

The concentrations of tebuconazole, copper, DOC and TN in the eluates from TS-2 experiments at different $\mathrm{L} / \mathrm{A}$ ratios decrease in the following order: L/A $2.2 \mathrm{~cm}^{3} / \mathrm{cm}^{2}>\mathrm{L} / \mathrm{A}$ $5 \mathrm{~cm}^{3} / \mathrm{cm}^{2}>\mathrm{L} / \mathrm{A} 8 \mathrm{~cm}^{3} / \mathrm{cm}^{2} \sim \mathrm{L} / \mathrm{A} 9 \mathrm{~cm}^{3} / \mathrm{cm}^{2}$. A repeated series of experiments using different L/A ratios confirmed that tebuconazole emissions increase with $\mathrm{L} / \mathrm{A}$ ratios (see Table 2 and Figure 2a). This is in agreement with

Table 3 Overview on the parameters of the leaching tests

\begin{tabular}{|c|c|c|c|c|c|c|}
\hline \multirow[t]{2}{*}{ Test procedure } & \multirow[t]{2}{*}{$\begin{array}{l}\text { Name of the } \\
\text { experiment }\end{array}$} & \multirow[t]{2}{*}{ Number } & \multirow{2}{*}{$\begin{array}{l}\text { Test specimens } \\
\text { (dimensions) } \\
{\left[\mathrm{cm}^{3}\right]}\end{array}$} & \multirow{2}{*}{$\begin{array}{l}\text { Test specimens per } \\
\text { test assembly } \\
\text { [number] }\end{array}$} & \multirow{2}{*}{$\begin{array}{l}\text { Duration of storage } \\
\text { after treatment } \\
\text { [weeks] }\end{array}$} & \multirow{2}{*}{$\begin{array}{l}\mathrm{L} / \mathrm{A} \\
{\left[\mathrm{cm}^{3} / \mathrm{cm}^{2}\right]}\end{array}$} \\
\hline & & & & & & \\
\hline \multirow[t]{8}{*}{ TS-2 } & L/A 8 (ECN) & 3 & $2.5 \times 5 \times 15$ & 1 & 17 & 8 \\
\hline & L/A 8 & 3 & & 2 & 7 & 8 \\
\hline & L/A 2.2 & 1 & & 3 & 7 & 2.2 \\
\hline & L/A 5 & 1 & & 3 & 7 & 5 \\
\hline & L/A 9 & 1 & & 2 & 7 & 9 \\
\hline & L/A 8 rep & 2 & & 2 & 39 & 8 \\
\hline & L/A 2.2 rep & 2 & & 3 & 39 & 2.2 \\
\hline & L/A 5 rep & 1 & & 3 & 39 & 5 \\
\hline \multirow[t]{3}{*}{ OECD 313} & OECD 313 & 3 & $1.5 \times 2.5 \times 5$ & 5 & 8 & 2.5 \\
\hline & OECD $313^{a}$ & 1 & $2.5 \times 5 \times 15$ & 1 & 8 & 2.5 \\
\hline & OECD $313^{a}$ & 1 & & 1 & 68 & 2.5 \\
\hline
\end{tabular}

Tests were performed at BAM unless otherwise stated in the name of the experiment; 'rep' stands for repeated experiments. The temperature was $20^{\circ} \mathrm{C} \pm 2^{\circ} \mathrm{C}$ in all experiments.

${ }^{a}$ 'Duration of storage' refers to treated test specimens. SD, standard deviation $\left(\mathrm{mg} / \mathrm{m}^{2}\right)$; 'control', experiment with untreated wood; OECD 313 , test specimens $\left(1.5 \times 2.5 \times 5 \mathrm{~cm}^{3}\right) ;$ OECD $313^{\mathrm{a}}$, test specimen as in TS-2 $\left(2.5 \times 5 \times 15 \mathrm{~cm}^{3}\right)$. 

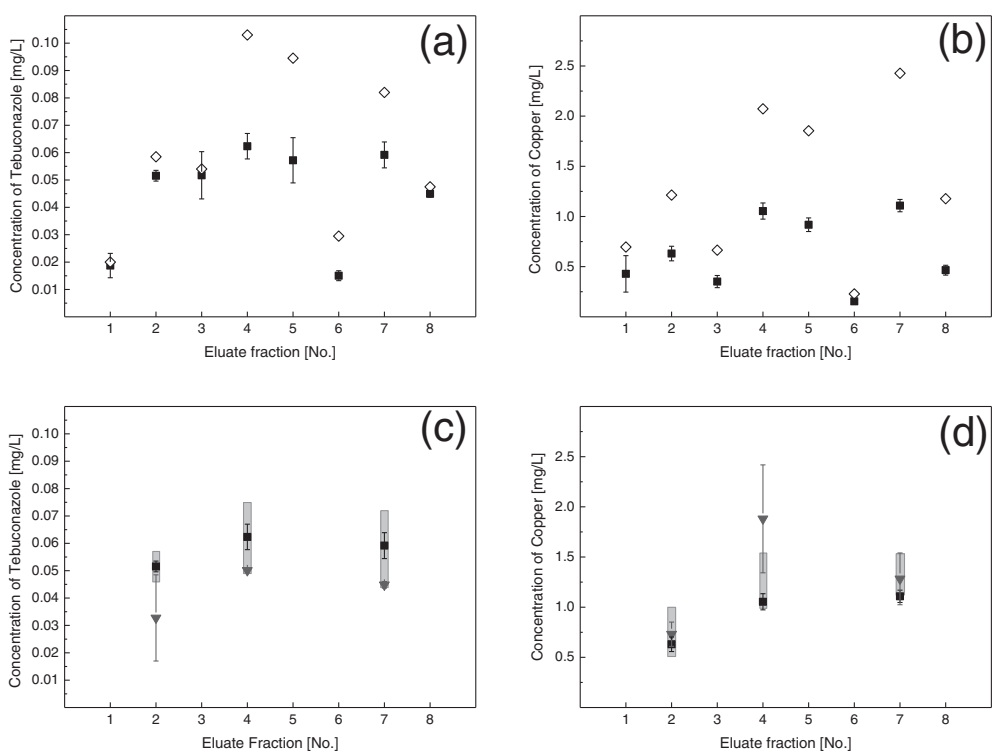

Figure 3 Concentration of tebuconazole and copper in eluate fractions of TS- 2 experiments. Concentration of tebuconazole (a and $\mathbf{c}$ ) and copper ( $\mathbf{b}$ and $\mathbf{d}$ ) in eluate fractions of TS-2 experiments (mean values, standard deviations as error bars) at L/A $=8 \mathrm{~cm}^{3} / \mathrm{cm}^{2}$ and $20^{\circ} \mathrm{C}$. Upper row: Comparison of test results after 7 weeks of storage of the test specimens prior to the leaching test $[n=3$, presented as quadrates ( $(\mathbf{\square})]$ and 39 weeks of storage $[n=2$, presented as diamonds $(\nabla)]$. Lower row: data from BAM experiments obtained after 7 weeks of storage $[n=3$, presented as quadrates

(-)] compared to selected eluate fractions from ECN experiments obtained after 17 weeks of storage $[n=3$, presented as triangles ( $\boldsymbol{\nabla})]$. Grey background indicates the range of the average value for the experiment after 7 weeks of storage \pm 2.8 -fold standard deviation.

previous experiments [11]. Cumulative emissions of DOC and $\mathrm{TN}$ were in similar ranges for all test assemblies of treated wood of each test series rather independent from the L/A ratio. Although leaching of copper differs considerably between the series of experiments, the emissions of copper decreased with increasing L/A ratios in both series of experiments (see Figure 2b). This has not been described so far, and it is assumed to be related to higher concentrations of organic substances as indicated by DOC and TN concentrations of the eluates at low L/A ratios. Leaching of copper is strongly related to the concentrations of DOC and $\mathrm{TN}$ in the eluates, whereas co-elution with organic substances is less important for tebuconazole (see Table 4). The normalised emission curves, i.e. emission rates given as percentage of the concentration in the first eluate versus duration of the test, are rapidly decreasing and very similar for copper, $\mathrm{DOC}$ and $\mathrm{TN}$, whereas the progression of the curves for tebuconazole is more gently dipping (not shown). Similar curve progression also supports the assumption that copper and organic substances are co-eluted. This is in agreement with the results reported by Lupsea et al. [20,21]. Increased emission of copper due to co-elution with DOC has been observed by van Zomeren et al. [22], Tiruta-Barna and Schiopu [23] and Lupsea et al. [20]. Co-elution of copper and organic substances, including nitrogenous substances, is supported by binding reactions as described by Lupsea et al. [20,21]. Therefore, the observation on copper emissions is related to the actual composition of the wood preservative that was used for the experiments.

\section{Ageing of treated test specimens}

The first series of TS-2 experiments was performed after 7 and 17 weeks of storage of the treated test specimens at BAM and ECN, respectively. A second series of experiments was performed at BAM using test specimens after 39 weeks of storage (see Table 3). The emissions of tebuconazole were in similar ranges in both series of TS-2 experiments with the exception of the data from the repeated experiments at $\mathrm{L} / \mathrm{A}=8 \mathrm{~cm}^{3} / \mathrm{cm}^{2}$ (see Figure 2a). It was noticed that the copper emissions were higher in the repeated experiments at all L/A ratios tested. This

Table 4 Correlation of concentrations of copper and tebuconazole with DOC and TN in eluates from TS-2 experiments

\begin{tabular}{llllll}
\hline $\begin{array}{l}\text { Storage of treated } \\
\text { test specimens }\end{array}$ & $\begin{array}{l}\text { Number } \\
\text { of eluates }\end{array}$ & \multicolumn{4}{l}{ Correlation coefficients for concentrations in eluates } \\
\cline { 2 - 6 } & Cu/DOC & Cu/TN & Tebuconazole/DOC & Tebuconazole/TN \\
\hline 7 weeks & 48 & 0.973 & 0.971 & 0.561 & 0.553 \\
39 weeks & 40 & 0.982 & 0.911 & 0.639 & 0.673 \\
\hline
\end{tabular}


observation was confirmed by OECD 313 experiments that were performed after 8 and 68 weeks of storage (see Figure 2b). Emissions of DOC and TN were lower in the second series of both types of experiments (see Table 2).

Possibly, the observed differences in the leachability of compounds were caused by ageing of the treated test specimens. However, higher emissions of copper in the second series of experiments were unexpected, since binding of copper in wood, so-called 'fixation', is expected to proceed with time and is known to reduce its leachability [5]. This result also contradicts the assumption that copper emissions are related to the DOC concentrations that were lower in the second series of experiments. The results cannot be explained by any deviation during the experiments or analysis of the eluates. There are two options to explain this result: the constituents of the wood preservative were not equally distributed in the stakes, e.g. copper fixation was less effective if ethanolamine did not penetrate into the middle sections of the stakes that were investigated in the second series of the experiments. Another option is that the composition of DOC originating from the wood and the wood preservative, i.e. the availability of functional groups for binding of copper, is changing with time. This is a question for further research.

The observed effect of ageing of test specimens is probably related to the applied wood preservative and its chemical reactions with wood components.

Chemical changes like binding reactions of the components of the wood preservative and evaporation of organic substances are supposed to take place during storage. Experiments of Lupsea et al. [20] revealed different leachability of substances possessing phenolic and carboxylic groups for untreated wood specimens that had been stored for different periods of time. Changes in the leachability of copper and tebuconazole were also related to these differences.

Leaching of components from treated wood is a complex process that is influenced by the chemical composition of the wood [20,21]. This composition does not only depend on the origin of the wood (e.g. species and growth conditions) and the components of wood preservatives but also on ageing of the wood.

\section{Conclusions}

Results from leaching experiments with treated wood are likely to vary considerably due to the inhomogeneity of wood that has to be used as test specimens. This can only slightly be compensated by using combinations of several test specimens in a test assembly, but cannot be circumvented. In addition, differences in the test results are acceptable to a certain degree if the aim of the test is a general description of leaching processes. Test specimens of the same origin and storage time have to be used if minor differences between wood preservatives have to be detected.

Despite the slight differences in the test conditions and test duration, the results of TS-2 and OECD 313 experiments are similar with regard to the total cumulative emission after 36 and 29 days, respectively. Both procedures indicate diffusion-controlled leaching of the target substances.

The robustness validation within CEN has led to a total test duration of 64 days in the final version of the TS-2 method while the TS-2 experiments during this study lasted 36 days. That is supposed to cause slightly higher total emissions due to the longer test duration, but the cumulative emission and the flux will remain comparable at comparable test duration.

Both the TS- 2 and the OECD 313 test procedures are suitable to describe leaching characteristics of substances emitted from treated wood. The results can be used to fulfil the requirements of the Construction Products Regulation as well as the Biocidal Products Regulation for estimations for which laboratory data are considered appropriate, i.e. data from TS-2 experiments can replace data from OECD 313 experiments and vice versa. It is expected that this applies also for other types of wood preservatives than the one included in this study.

Certain results are probably related to the applied wood preservative, i.e. additional components in the preservative. The effect of changes of $\mathrm{L} / \mathrm{A}$ ratios on copper emission can be related to the amount and composition of coeluting DOC. Changes of the chemical composition of the test specimens during ageing of the treated test specimens are assumed to cause increased leachability of copper. Therefore, a detailed description on preparation and conditioning of test specimens is required for leaching tests with treated wood. It has to be considered that leaching processes also depend on the actual composition of the test specimens when experimental leaching data are used to derive leaching characteristics.

\section{Methods \\ Wood preservative}

A water-based wood preservative of the $\mathrm{Cu} /$ triazole type containing $10 \%$ copper, $0.39 \%$ tebuconazole and ethanolamine was provided by a company for this study. The content of the active substances was confirmed by chemical analysis of the product. Tebuconazole (CAS 107534-96-3) is approved as an active substance for wood preservatives according to the European regulations on biocidal products. It acts as a fungicide. The molecular mass amounts to $307.8 \mathrm{~g} / \mathrm{mol}$, the water solubility of tebuconazole (technical) is $0.029 \mathrm{~g} / \mathrm{l}(\mathrm{pH} 7)$, the $\log K_{\mathrm{OW}}$ is 3.5 $\left(20^{\circ} \mathrm{C}\right)\left(K_{\text {Ow: }}\right.$ octanol/water partition coefficient) and the vapour pressure is $1.7 \times 10^{-6} \mathrm{~Pa}\left(20^{\circ} \mathrm{C}\right)$. The substance is 
stable towards photolysis in aqueous solution and stable towards hydrolysis between $\mathrm{pH} 5$ and 9 at $25^{\circ} \mathrm{C}$ [19].

\section{Preparation of test specimens}

Test specimens of Pinus sylvestris (sapwood) $(50 \times 5 \times$ $2.5 \mathrm{~cm}^{3}$, referred to as 'stakes') were treated by vacuum pressure impregnation with a $2.12 \%(w / w)$ solution of the wood preservative in water in a pilot plant. The retention of the preservative was $15.1 \pm 0.2 \mathrm{~kg} / \mathrm{m}^{3}$ which is the amount required for use class 4 according to EN 335 [24] (i.e. wood intended to be in permanent contact with the ground or water). The test specimens were conditioned according to prEN $252[25]$ at $20^{\circ} \mathrm{C} \pm 2^{\circ} \mathrm{C}$, $65 \% \pm 5 \%$ relative humidity for a minimum of 7 weeks. Thirty-nine days after treatment, the specimens were cut to pieces of $15 \times 5 \times 2.5 \mathrm{~cm}^{3}$ and sealed at the cut faces using a mixture of Sigillon I and II (polyurethane-based varnish) since these areas are actually not exposed to water in a construction work. The OECD 313 experiments were performed using one test specimen from this batch, but mainly using test specimens of $5 \times 2.5 \times 1.5 \mathrm{~cm}^{3}$ as defined in EN 113 [26] that were vacuum-impregnated with the same preservative. The stakes and the test specimens according to EN 113 originate from different trees.

\section{Leaching experiments}

After conditioning, the treated test specimens were used to test the influence of the ambient temperature at ECN Petten (NL), whereas the tests under variation of L/A were performed at BAM. For the first series of experiments, the two 'outer' subsamples from the ends of identical stakes were allocated to the laboratories. The subsamples from the middle sections were kept as a reserve and were used for repeated experiments at BAM. The reported results originate from experiments at BAM if not specified otherwise.
The test specimens were placed in either glass or stainless steel containers and covered with the water volume required to achieve the specified L/A ratios. It was necessary to use different numbers, i.e. one to three test specimens per test assembly to achieve the required L/A ratios for the TS-2 tests in the test vessels. Certain test parameters are illustrated in Figure 4. The OECD 313 tests were performed in parallel to the first series of TS-2 tests. Water renewal schemes for TS-2 and OECD 313 experiments are given in Table 1. Mass data were recorded for the test specimens in OECD 313 experiments. Further details on experimental setup parameters are given in Table 3.

\section{Analysis of eluates}

The eluates from the experiments at BAM were analysed for DOC and TN by catalytic combustion and non-dispersive infrared (NDIR) detection according to EN 1484:1997 [27] using a Shimadzu TOC-VCPH analyzer (Shimadzu Corporation, Nakagyo-ku, Kyoto, Japan). Eluate samples from all laboratories were analysed at BAM for tebuconazole by liquid chromatography coupled with MS detection (Agilent 1100 Series with a 6130 Quadrupole LC/MS, Agilent Technologies, Santa Clara, CA, USA) without further sample preparation. The samples were separated on a reversed phase column (Phenomenex Luna C18(2) $3 \mu \mathrm{m}, 50 \times 2 \mathrm{~mm}$, Phenomenex, Aschaffenburg, Germany) and eluted by a gradient of $0.2 \%$ acetic acid in water and acetonitrile. Quantification of tebuconazole was based on the signal at $m / z$ 308. Each sample was analysed twice at minimum. The LOD was $0.0035 \mathrm{mg} / \mathrm{l}$ and relative standard deviation of parallel injections of samples was $\leq 2 \%$. The samples for the analysis of copper were stabilised with a few drops of nitric acid and analysed at BAM by atomic absorption spectrometry using a UNICAM 696 AA spectrometer (Thermo Scientific, Waltham, MA, USA) (LOD $0.17 \mathrm{mg} / \mathrm{l}$, relative standard deviation $2 \%$ ).
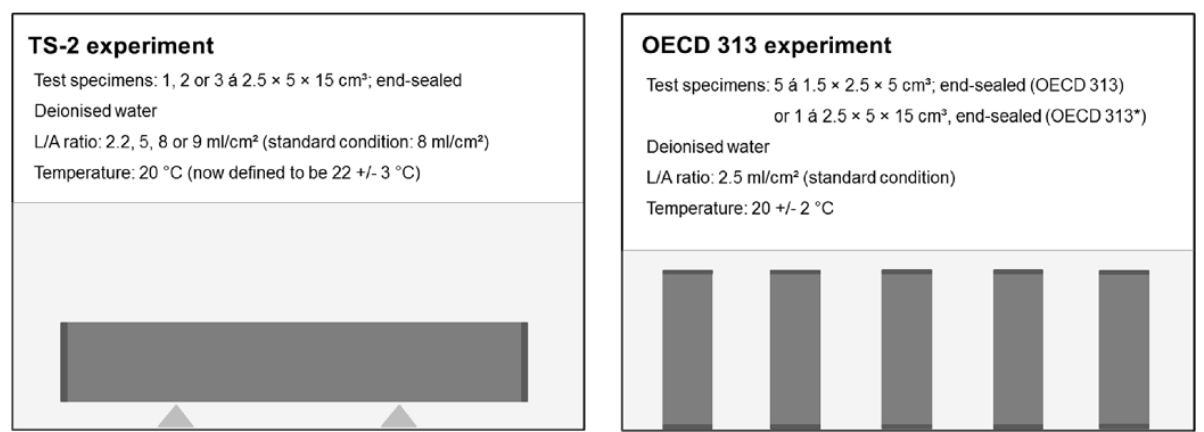

Figure 4 Schemes for experiments according to TS-2 and OECD 313. Exposed surface areas are $225 \mathrm{~cm}^{2}$ for each test specimen of $2.5 \times 5 \times 15 \mathrm{~cm}^{3}$ and $40 \mathrm{~cm}^{2}$ for each test specimen of $1.5 \times 2.5 \times 5 \mathrm{~cm}^{3}$, i.e. $200 \mathrm{~cm}^{2}$ for a set of five test specimens. 


\section{Abbreviations}

BAM: Bundesanstalt für Materialforschung und -prüfung; DOC: dissolved organic carbon; ECN: Energy Research Centre of the Netherlands); L/A: liquid (water) volume/exposed surface area; LOD: limit of detection; SD: standard deviation; TN: total nitrogen.

\section{Competing interests}

The authors declare that they have no competing interests.

\section{Authors' contributions}

All authors were substantially involved in the conception and design of the study and interpretation of the data. UK, AZ and US were responsible for the acquisition of the data. US performed the analysis of the data and drafted the manuscript. UK, $\mathrm{AZ}$ and $\mathrm{OH}$ critically revised the manuscript. All authors read and approved the final manuscript.

\section{Acknowledgements}

This work was partly funded by the EU Commission (Project No. 11810594). The authors thank the producer for the support with the wood preservative and T. Sommerfeld, Y. de Laval, K. Nordhauß and P.A. Bonouvrie who carefully performed the leaching tests and analysis of the eluates.

\section{Author details}

'Division 4.1 Biodeterioration and Reference Organisms, BAM Federal Institute for Materials Research and Testing, Unter den Eichen 87, D-12205 Berlin, Germany. ${ }^{2}$ Division 4.3, Contaminant Transfer and Environmental Technologies, BAM Federal Institute for Materials Research and Testing, Unter den Eichen 87, D-12205 Berlin, Germany. ${ }^{3}$ Department of Environmental Assessment, ECN, Westerduinweg 3, 1755 LE Petten, the Netherlands. "Waste and Soil, DHI, Agern Allé 5, DK-2970 Hørsholm, Denmark.

Received: 9 May 2014 Accepted: 28 September 2014

Published online: 11 October 2014

\section{References}

1. Regulation (EU) No. 305/2011 of the European Parliament and of the Council of 9 March 2011 laying down harmonised conditions for the marketing of construction products and repealing Council Directive 89/106/EEC. http://eur- lex.europa.eu/LexUriServ/LexUriServ.do?uri= OJ: L:2011:088:0005:0043:EN:PDF.

2. European Commission (EC): Mandate M/366. Horizontal complement to the mandates to CEN/CENELEC, concerning the execution of standardization work for the development of horizontal standardized assessment methods for harmonized approaches relating to dangerous substances under the Construction Products Directive (CPD). Emissions to indoor air, soil, surface water and ground water. Brussels: European Commission; 2005

3. Hjelmar O, Hyks J, Wahlström M, Laine-Ylijoki J, van Zomeren A, Comans R, Kalbe U, Schoknecht U, Krüger O, Grathwohl P, Wendel T, Abdelghafour M, Méhu J, Schiopu N, Lupsea M: Robustness validation of TS-2 and TS-3 developed by CEN/TC351/WG1 to assess release from products to soil, surface water and groundwater. Report 2013. https://www.nen.nl/web/file? uuid=9355006a-a1bc-416e-bd8c.

4. FprCEN/TS 16637-2:2013: Construction Products - Assessment of Release of Dangerous Substances - Part 2: Horizontal Dynamic Surface Leaching Test (Temporarily Named TS-2). CEN/TC 351: 2013. CEN-CENELEC Management Centre Brussels.

5. Lebow S: Leaching of Wood Preservative Components and Their Mobility in the Environment - Summary of Pertinent Literature. Madison: Gen. Tech. Rep. FPL-GTR-93. Forest Service, Forest Products Laboratory, U.S. Department of Agriculture; 1996.

6. Hingston JA, Moore J, Bacon A, Lester JN, Murphy RJ, Collins CD: The importance of the short-term leaching dynamics of wood preservatives. Chemosphere 2002, 47(5):517-523.

7. Hingston JA, Bacon A, Moore J, Collins CD, Murphy RJ, Lester JN: Influence of leaching protocol regimes on losses of wood preservative biocides. Bull Environ Contam Toxicol 2002, 68(1):118-125.

8. Lebow ST, Cooper P, Lebow PK: Variability in Evaluating Environmental Impacts of Treated Wood. Madison: Res. Pap. FPL-RP-620. Forest Service, Forest Products Laboratory, U.S. Department of Agriculture; 2004.

9. Schoknecht U, Mathies H, Wegner R, Melcher E, Seidel B, Kussatz C, Maletzki D: The Influence of Test Parameters on the Emission of Biocides from
Preservative-Treated Wood in Leaching Tests. UFOPLAN 20367 441. BAM Berlin: Research report; 2004.

10. Waldron L, Cooper PA, Ung TY: Prediction of long-term leaching potential of preservative-treated wood by diffusion modelling. Holzforschung 2005, 50(5):81-588.

11. Schoknecht $U$, Mathies $H$, Morsing $N$, Lindegaard $B$, van der Sloot $H A$, van Zomeren A, Deroubaix G, Legay S, Tadeo JL, Garcia-Valcárcel Al, Gigliottti G, Zadra C, Hajšlová J, Tomaniová M, Wegner R, Bornkessel C, Fürhapper C: Inter-laboratory Evaluation of Laboratory Test Methods to Estimate the Leaching from Treated Wood. BAM Berlin: European Grant Agreement no. 04/375757/C4, Report; 2005.

12. Townsend TG, Solo-Gabriele H: Environmental Impacts of Treated Wood. Boca Raton: CRC Press; 2006

13. Lebow $S$, Lebow $P$, Foster D: Estimating preservative release from treated wood exposed to precipitation. Wood Fiber Sci 2008, 40(4):562-571.

14. Regulation (EU) No 528/2012 of the European Parliament and of the Council of 22 May 2012 concerning the making available on the market and use of biocidal products. http://eur-lex.europa.eu/legal-content/EN/ TXT/PDF/?uri=CELEX:32012R0528\&qid =1413179620144\&from=EN

15. Wood Held in the Storage Yard After Treatment and Wooden Commodities Exposed in Use Class 3 (Not Covered, Not In Contact with the Ground) - Laboratory Method. CEN/TC 38: 2008. CEN-CENELEC Management Centre Brussels.

16. CEN TS 15119-2:2012: Durability of Wood and Wood-Based Products, Determination of Emissions from Preservative Treated Wood to the Environment - Part 2: Wooden Commodities Exposed in Use Class 4 or 5 (In Contact with the Ground, Fresh Water or Sea Water) - Laboratory Method. CEN/TC 38: 2012. CEN-CENELEC Management Centre, Brussels; 2007.

17. OECD 313:2007: Estimation of Emissions from Preservative-Treated Wood to the Environment: Laboratory Method for Wooden Commodities That Are Not Covered And Are In Contact with Fresh Water or Seawater. OECD; 2007.

18. OECD Guidance for industry data submissions on the estimation of emissions from wood preservative-treated wood to the environment: for wood held in storage after treatment and for wooden commodities that are not covered and are not in contact with ground (July 2009), Series on Testing and Assessment No. 107. http://www.oecd.org/dataoecd/42/ 31/43411595.pdf.

19. Assessment report: tebuconazole (PT 8). http://ec.europa.eu/environment/ biocides/.

20. Lupsea M, Mathies H, Schoknecht U, Tiruta-Barna L, Schiopu N: Biocide leaching from CBA treated wood - a mechanistic interpretation. Sci Total Environ 2013, 444:522-530.

21. Lupsea M, Tiruta-Barna L, Schiopu N, Schoknecht U: Modelling inorganic and organic biocide leaching from CBA-amine (copper-boron-azole) treated wood based on characterisation leaching tests. Sci Total Environ 2013, 461-462:645-654.

22. van Zomeren $\mathrm{A}$, Meeussen $\mathrm{HCL}$, van der Sloot $\mathrm{HA}$ : Characterisation of the leaching behaviour of preserved wood and results of modelling release. In Schoknecht et al.: Interlaboratory Evaluation of Laboratory Test Methods to Estimate the Leaching from Treated Wood. European Grant Agreement no. 04/375757/C4. 2005.

23. Tiruta-Barna $L$, Schiopu N: Modelling inorganic biocide emission from treated wood. J Hazard Mater 2011, 192:1476-1483.

24. EN 335:2013: Durability of Wood and Wood-Based Products - Use Classes: Definitions, Application to Solid Wood and Wood-Based Products. CEN/TC 38: 2013. CEN-CENELEC Management Centre Brussels.

25. prEN 252:2012: Field Test Method for Determining the Relative Protective Effectiveness of a Wood Preservative in Ground Contact. CEN/TC 38: 2012 CEN-CENELEC Management Centre Brussels.

26. EN 113:1996: Wood Preservatives - Method of Test for Determining the Protective Effectiveness Against Wood Destroying Basidiomycetes - Determination of the Toxic Values. CEN/TC 38: 1996. CEN-CENELEC Management Centre Brussels.

27. EN 1484:1997: Water Analysis - Guidelines for the Determination of Total Organic Carbon (DOC) and Dissolved Organic Carbon (DOC). CEN/TC 230: 1997. CEN-CENELEC Management Centre Brussels.

doi:10.1186/s12302-014-0025-2

Cite this article as: Schoknecht et al:: Laboratory leaching tests on treated wood according to different harmonised test procedures. Environmental Sciences Europe 2014 26:25. 